\title{
Pengungkapan Corporate Social Responsibility terhadap Tax Aggressiveness
}

\author{
Dwi Lestari Limbong a and Ely Kartikaningdyah ${ }^{\mathrm{b}, *}$ \\ a Manajemen Bisnis, Politeknik Negeri Batam, dwilestari1650@ gmail.com, Indonesia \\ ${ }^{\mathrm{a}}$ Manajemen Bisnis, Politeknik Negeri Batam,ely@polibatam.ac.id, Indonesia
}

\begin{abstract}
The aim of this study is to examine the effect of corporate social responsibility (CSR) to corporate tax aggressiveness. The independent variable is used in this study is corporate social responsibility disclosure. While the dependent variable in this study is tax aggressiveness that measured using two effective tax rates measures. This study is a replication of the study by Lanis and Richardson (2012) and use 151 manufacturing companies that listed on the Indonesia Stock Exchange as the sample. Samples were selected by purposive sampling method and finally obtained 62 manufacturing companies per year that fulfill the criterias. Data were analyzed using ordinary least square regression analysis model.
\end{abstract}

Keywords: corporate social responsibility, tax aggressiveness

\section{Pendahuluan}

Pajak merupakan kontribusi wajib kepada negara yang terutang oleh orang pribadi atau badan sebagai wajib pajak yang bersifat memaksa berdasarkan undang-undang dengan tidak mendapatkan timbal balik secara langsung dan digunakan untuk keperluan negara bagi kemakmuran rakyat (Pasal 1 UU No. 28 tahun 2007). Bagi perusahaan, pajak merupakan suatu beban yang paling signifikan yang dikeluarkan oleh perusahaan yang akan berdampak langsung pada pendapatan suatu perusahaan. Dalam upaya efisiensi beban pajak, banyak perusahaan yang melakukan penghindaran pajak.

Penghindaran pajak didefinisikan oleh Dyreng et al. (2008) sebagai segala sesuatu yang dilakukan perusahaan dan berakibat pengurangan terhadap pajak perusahaan. Xynas (2011) membedakan definisi antara penghindaran pajak (tax avoidance) dan penggelapan pajak (tax evasion). Menurut Xynas (2011) penghindaran pajak merupakan salah satu usaha untuk mengurangi beban pajak yang bersifat legal sementara itu penggelapan pajak merupakan salah satu cara untuk mengurangi beban pajak yang bersifat tidak legal.
Tanggung jawab sosial dan lingkungan adalah komitmen perseroan untuk berperan serta dalam pembangunan ekonomi berkelanjutan guna meningkatkan kualitas kehidupan dan lingkungan yang bermanfaat, baik bagi perseroan sendiri, komunitas setempat, maupun masyarakat pada umumnya (Pasal 1 angka 3 UU No. 40 Tahun 2007).

Penelitian empiris terdahulu terkait pengaruh CSR terhadap tax aggressiveness mempunyai hasil yang negatif, seperti yang dilakukan oleh Yoehana (2013) dalam konteks perusahaan manufaktur yang ada di Bursa Efek Indonesia. Penelitian yang dilakukan di luar negeri dengan hasil yang negatif juga seperti Lanis dan Richardson (2012) yang mengambil sampel wajib pajak badan yang listing di Australia. Hasil dari penelitian tersebut bahwa pajak perusahaan tidak berpengaruh pada corporate social responsibility.

Penelitian ini merupakan replikasi dari penelitian Lanis dan Richardson yang menggunakan sampel perusahaan yang listing di Australia dari tahun 20082009. Rumusan masalah dalam penelitian ini adalah bagaimana pengungkapan corporate social responsibility terhadap tax aggresiveness yang menggunakan sampel perusahaan manufaktur yang listing di Bursa Efek Indonesia periode 2010-2013.

\footnotetext{
*Corresponding author. E-mail: ely@polibatam.ac.id
} 


\section{Kajian Literatur}

\section{Corporate social responsibility}

Corporate social responsibility didefinisikan sebagai "'bagaimana perusahaan memperhitungkan dampak sosial dan lingkungan dalam cara perusahaan tersebut beroperasi, memaksimalkan manfaat dan meminimalkan kerugian" (Pemerintah UK dalam KPMG, 2007). Peraturan corporate social responsibility di Indonesia diatur dalam UU No. 40 tahun 2007 Pasal 74 Tentang Perseroan Terbatas. Undang undang tersebut mengatur tentang perusahaan yang menjalankan kegiatan usahanya dan melakukan tanggung jawab social dan lingkungan.

\section{Tax Aggressiveness}

Hlaing (2012) mendefinisikan agresivitas pajak sebagai kegiatan perencanaan pajak semua perusahaan yang terlibat dalam usaha mengurangi tingkat pajak yang efektif. Jika perusahaan dianggap menghindari pajak, misalnya dengan membentuk skema atau pengaturan dengan tujuan tunggal atau dominan untuk menghindari pajak, hal ini perusahaan tidak dianggap membayar pajak tersebut secara wajar kepada pemerintah untuk membantu pembiayaan fasilitas publik.

\section{Pengembangan Hipotesis}

\section{Pengungkapan corporate social responsibility terhadap tax aggressiveness}

Penelitian terdahulu terkait pengaruh corporate social responsibility yang dilakukan memiliki hasil yang sama (negatif). Hasil penelitian yang menemukan pengaruh negatif antara corporate social responsibility terhadap tax aggressiveness dilakukan oleh Lanis dan Richardson (2012). Avi-Yonah (2008) dalam Lanis dan Richardson (2012) menyatakan bahwa pajak perusahaan hanya dapat dikaitkan dengan corporate social responsibility jika pembayaran pajak dilakukan perusahaan memang memiliki implikasi untuk masyarakat luas. Mengambil sudut pandang bahwa corporate adalah "dunia nyata" yang entitasnya dengan kewajiban sosial dan pembayaran pajak perusahaan tidak mempengaruhi masyarakat. Kewajiban corporate social responsibility mengharuskan perusahaan harus membayar secara wajar pajak kepada pemerintah di negara mana perusahaan mereka beroperasi.

Lanis dan Richardson (2012) berpendapat dalam membayar pajak perusahaan seharusnya memiliki beberapa pertimbangan etika untuk masyarakat dan stakeholder lainnya. Semakin tinggi tingkat pengungkapan corporate social responsibility yang dilakukan oleh perusahaan, diharapkan perusahaan tidak semakin agresif terhadap pajak (Yoehana, 2013). Berdasarkan penjelasan tersebut, maka hipotesis yang diajukan adalah:

H1: Corporate social responsibility berpengaruh negatif terhadap tax aggressiveness.

\section{Metode Penelitian}

Model penelitian digunakan untuk menguji hubungan antara corporate social responsibility dengan tax aggressiveness

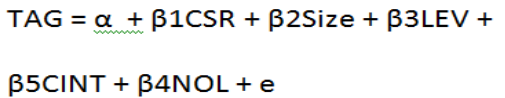

Keterangan:

TAG : agresivitas pajak perusahaan $i$ tahun ke- $t$ yang diukur oleh proksi ETR.

CSR : Pengungkapan item corporate social responsibility $i$ tahun ke- $t$

SIZE : Ukuran perusahaan diukur sebesar nilai log total aset

LEVERAGE : Rasio dari utang jangka panjang terhadap total aset

CINT : Proporsi property, plant, and equipment terhadap total aset tetap perusahaan $i$ tahun ke- $t$

\section{Operational variabel}

Variabel dependen pada penelitian ini adalah tax aggressiveness yang diukur menggunakan effective tax rate mengacu pada penelitian yang dilakukan oleh Chen et al. (2010) dan Lanis and Richardson (2012). Untuk menghitung effective tax rate, digunakan rumus yang mengacu pada penelitian Chen et al. (2010) dan Lanis \& Richardson (2012), sebagai berikut:

ETR $=\frac{\text { Beban pajak penghasilan }}{\text { Pendapatan sebelum pajak }}$

Variabel independen pada penelitian ini adalah corporate social responsibility yang diukur dengan 
proksi check list mengacu pada penelitian yang dilakukan oleh Sembiring (2005).

Variabel kontrol pada penelitian ini meliputi ukuran perusahaan (SIZE) diukur sebesar nilai log total assets. Leverage (LEVERAGE) diukur dengan membandingkan hutang jangka panjang dengan total asset dan capital intensity diukur dengan total aset bersih dibagi total aset mengacu pada penelitian yang dilakukan oleh Lanis and Richardson (2012).

Tabel 1

Pengukuran Variabel yang Digunakan

\begin{tabular}{lll}
\hline TAG & Tax Aggresiveness & $\begin{array}{l}\text { Beban Pajak } \\
\text { Penghasilan/Pendapatan } \\
\text { sebelum Pajak }\end{array}$ \\
CSR & $\begin{array}{l}\text { Corporate Social } \\
\text { Responsibility }\end{array}$ & List \\
SIZE & Ukuran Perusahaan & $\begin{array}{l}\text { Log Value of Asset } \\
\text { Long Term Debt/total asset } \\
\text { LEVERAGE }\end{array}$ \\
CINT & Capital Intensity & $\begin{array}{l}\text { Total Aset Tetap } \\
\text { Cersih/Total Aset }\end{array}$ \\
\hline
\end{tabular}

\section{Data dan sampel}

Data yang digunakan dalam penelitian ini adalah data panel. Sampel yang digunakan adalah perusahaan manufaktur yang listing di Bursa Efek Indonesia dari periode 2010-2013. Total sampel yang diperoleh sebanyak 62 perusahaan di mana setiap tahunnya jumlah sampel yang diperoleh sama. Hasil tersebut diperoleh dari perusahaan yang listing selama periode pengamatan sebanyak 151 perusahaan dikurangi kriteria sebagai berikut: Perusahaan yang tidak mempublikasikan laporan keuangan dan tahunan secara lengkap sebanyak 69 perusahaan. Perusahaan yang pencatatan laporan keuangannya berakhir selain tanggal 31 Desember sebanyak 8 perusahaan. Perusahaan yang menyajikan laporan keuangan dengan mata uang selain Rupiah sebanyak 12 perusahaan.

\section{Pembahasan}

\section{Pengungkapan corporate social responsibility terhadap tax aggressiveness}

Pengujian hubungan variabel independen terhadap variabel dependen menggunakan program Eviews dan hasil uji deskriptif disajikan pada Tabel 2 sedangkan hasil pengujian regresi disajikan dalam Tabel 3. Berdasarkan hasil uji asumsi klasik, hasil pengujian Kolmogorov-smirnov menunjukkan nilai signifikansi lebih besar dari 0,05 yaitu sebesar 0,216 yang menunjukkan bahwa data tersebar secara normal. Hasil uji multikolinearitas menunjukkan nilai VIF lebih kecil dari 10 sehingga disimpulkan tidak terjadi multikolinearitas antara variabel independen. Sedangkan hasil uji heterokedastisitas nilai varians residual lebih besar dari 0,05 ini berarti residual bersifat homokedastisitas. Begitu juga dengan uji autokorelasi yang menunjukkan kolom Durbin-Watson lebih besar dari 0,05 yaitu sebesar 2,071 .

Berdasarkan hasil uji statistik deskriptif pada tabel 2, maka dapat dilihat rata-rata ETR bernilai 51,75\% nilai ini lebih tinggi dari tarif pajak yang berlaku mulai tahun fiskal 2010 yaitu $25 \%$. Untuk variabel CSR, memiliki nilai rata-rata $23,09 \%$ menunjukkan bahwa nilai rata-rata lebih besar dari standar deviasi. Hal ini menunjukan bahwa kualitas data dari variabel tersebut baik.

Tabel 2

Descriptive Statistics

\begin{tabular}{lccccc}
\hline & N & Min & Max & Mean & $\begin{array}{c}\text { Std. } \\
\text { Deviation }\end{array}$ \\
\hline ETR & 248 & 7.605 & 8.267 & 0.517 & 5.537 \\
CSR & 248 & 0.050 & 0.835 & 0.230 & 0.158 \\
SIZE & 248 & 8.627 & 1.902 & 1.400 & 1.782 \\
LEV & 248 & 0.000 & 1.987 & 0.153 & 0.259 \\
CINT & 248 & 0.010 & 1.017 & 0.790 & 6.444 \\
\hline
\end{tabular}

Variabel kontrol penelitian ini ada tiga yaitu size, capital intensity dan leverage (LEV). Berdasarkan Tabel 2 pada variabel ukuran perusahaan (SIZE) ratarata perusahaan sampel memiliki ukuran perusahaan yang tidak jauh berbeda, hal ini terlihat dari standar deviasi yang sebesar 1.782.680. Nilai rata-rata leverage adalah 0,153138 ini menunjukkan pengembalian utang jangka panjang terhadap total aset perusahaan adalah $15,31 \%$. Nilai rata-rata capital intensity adalah 0,790113 menunjukan seberapa besar kekayaan perusahaan yang diinvestasikan dalam bentuk aset tetap adalah $79,01 \%$.

Hasil uji multikolinearitas menyatakan bahwa seluruh variabel penelitian tidak terdapat multikolinearitas karena nilai VIF seluruh variabel penelitian kurang dari 10. Hasil uji heteroskedasitas dengan menggunakan metode white heteroskedasticity menyatakan, bahwa seluruh variabel penelitian bebas heteroskedasitas karena nilai prob. Chi-Square Obs*R-Squared > 0,05.

Hasil penelitian menggunakan uji regresi pada Tabel 3 menunjukkan bahwa variabel corporate social responsibility memiliki hubungan positif dan signifikan terhadap variabel tax aggressiveness 
dengan nilai coefficient 2,946373 (Sig < 0,0011) sehingga hipotesis (H1) tidak terdukung.

Tabel 3

Uji Regresi

\begin{tabular}{lcccc}
\hline \multicolumn{1}{c}{ Variabel } & Coefficient & P-Value & ST Error & T Statistik \\
\hline CSR & 2,946373 & 0,0011 & 8,867608 & 3,322624 \\
SIZE & $-1,310654$ & 0,0134 & 0,524930 & $-2,496817$ \\
LEV & $-1,627125$ & 0,6101 & 3,185080 & $-0,510859$ \\
CINT & $-0,015150$ & 0,8469 & 0,078338 & $-0,193390$ \\
\multicolumn{4}{l}{ Hasil Uji Hausman } \\
\hline
\end{tabular}

$\mathrm{TAG}=\alpha+\beta 1 \mathrm{CSR}+\beta 2 \mathrm{Size}+\beta 3 \mathrm{LEV}+\beta 4 \mathrm{CINT}+\beta 5 \mathrm{NOL}+\mathrm{e}$

Hipotesis 1 menyatakan bahwa corporate social responsibility berpengaruh negatif terhadap tax aggressivenness. Penelitian ini menemukan bahwa corporate social responsibility berpengaruh positif terhadap tax aggressivenness. Variabel corporate social responsibility mempunyai nilai sig sebesar $0,0011<0,05$ dan memiliki nilai koefisien regresi sebesar 2,946373. Dari hasil tersebut $\mathrm{H}_{1}$ tidak berpengaruh. Hasil ini menunjukkan bahwa beberapa item CSR memang merupakan pengeluaran yang dapat dibebankan sebagai biaya yang dapat mengurangi penghasilan kena pajak. Hasil ini mendukung penelitian Femitasari (2013) yang menemukan pengaruh positif antara corporate social responsibility dengan tax aggressiveness. Variabel kontrol size mempunyai nilai sig sebesar 0,0134 < 0,05 dengan nilai koefisien regresi sebesar $-1,310654$. Hal ini menunjukkan bahwa size berpengaruh negatif dan signifikan terhadap tax aggressiveness, yang menandakan bahwa semakin besar ukuran perusahaan maka akan meningkatkan tax aggressiveness.

Variabel kontrol leverage mempunyai nilai sig sebesar 0,6101>0,05 dan memiliki nilai koefisien regresi sebesar -1,627125. Hal ini menunjukkan bahwa leverage tidak berpengaruh terhadap tax aggressiveness. Variabel kontrol capital intensity mempunyai nilai sig sebesar 0,8469>0,05 dan memiliki nilai koefisien regresi sebesar $-0,015150$. Hal ini menunjukkan bahwa capital intensity tidak berpengaruh terhadap tax aggressiveness.

\section{Kesimpulan}

Berdasarkan dari hasil penelitian tentang pengungkapan corporate social responsibility terhadap tax aggressiveness, maka dapat ditarik kesimpulan bahwa corporate social responsibility berpengaruh positif terhadap tax aggressiveness. Perusahaan yang menggunakan tindakan tanggung jawab sosial yang semata-mata untuk mendapatkan image yang positif agar perusahaan dapat melakukan penghindaran pajak. Keterbatasan dari penelitian ini meliputi: Pertama, penelitian ini hanya menggunakan sampel dari perusahaan manufaktur yang terdaftar di Bursa Efek Indonesia sehingga hasilnya tidak dapat digunakan secara umum untuk industri lainnya di Indonesia. Kedua, penelitian ini menggunakan effective tax rates sebagai satu-satunya proksi penghindaran pajak.

Untuk penelitian selanjutnya disarankan agar menggunakan sampel seluruh perusahaan yang terdaftar di Bursa Efek Indonesia sehingga hasilnya lebih mampu menggambarkan keadaan agresivitas pajak di Indonesia. Penelitian selanjutnya juga dapat menggunakan pengukuran lain sebagai proksi agresivitas pajak, misalnya boox tax differences. Penelitian selanjutnya dapat menambahkan variabel dan periode penelitian.

\section{References}

Armstrong, C. S., Jennifer L.Blouin, dan David F.Larcker. (2012). The incentives for tax planning. Journal of Accounting and Economics, Vol 53, 391-411.

Budiman, Judi, dan Setiyono. (2012). Pengaruh Karakter Eksekutif terhadap Penghindaran Pajak (Tax Avoidance). SNA XV.

Chen, S., Chen, X., Cheng, Q., Shevlin, T. (2010). Are Family Firms More Tax Aggressive Than Non-Family Firms? Journal of Financial Economics. 95, 41-61.

Dyreng, S., Hanlon, M., dan Maydew, E. L. (2008). Long-Run Corporate Tax Avoidance. The Accounting Review, Vol.83, 61-82.

Femitasari, Lina. 2013. Pengaruh Proporsi Dewan Komisaris Independen, Kepemilikan Institusional dan Corporate Social Responsibility terhadap Agresivitas Pajak. Skripsi, Fakultas Bisnis, Widya Mandala Catholic University.

Hadi, Nor. 2011. Corporate Social Responsibility (CSR). Edisi 1. Jakarta: Graha Ilmu.

Hanafi, U., \& Harto, P. (2013). Analisis Pengaruh Kompensasi Eksekutif, Kepemilikan Saham Eksekutif dan Preferensi Risiko Eksekutif terhadap Penghindaran Pajak Perusahaan. Diponegoro Journal Of Acconting Vol. 3, 1-11.

Hanlon, M., \& Heitzman, S. (2010). A Review of Tax Research. Journal of Accounting and Economics, 127 - 178

Hlaing, K.P. (2012). Organizational Architecture of Multinationals and Tax Aggressiveness, University of Waterloo. Canada.

Nachrowi, D. (2006). Pendekatan Populer dan Praktis Ekonometrika untuk Analisis Ekonomi dan Keuangan. Jakarta: Lembaga Penerbit Fakultas Ekonomi Universitas Indonesia.

Irawan, H.P. dan A. Farahmita. (2012). Pengaruh Kompensasi Manajemen dan Corporate Governance Terhadap Tax Avoidance. Skripsi, Fakultas Ekonomi, Universitas Indonesia.

Landry, S., Deslandes, M., \& Fortin, A. (2013). Tax Aggressiveness, Corporate Social Responsibility, and Ownership 
Structure. Journal of Accounting, Ethics \& Public Policy Vol 14, No 3.

Lanis, R., \& Richardson, G. (2012). Corporate social responsibility and tax aggressiveness: An empirical analysis. J. Account. Public Policy 31, 86-108.

Peraturan Pemerintah No. 47 Tahun 2012 tentang Tanggung Jawab Sosial dan Lingkungan Perseroan Terbatas ("PP 47/2012").

Puspita, S. R. \& Harto, P. (2013). Pengaruh Tata Kelola Perusahaan Terhadap Penghindaran Pajak. Diponegoro Journal of Acconting Vol. 3, 1-13.

Rustiarini, 2011. Pengaruh Struktur Kepemilikan Saham pada Pengungkapan Corporate Social Resposibility. AUDI Jurnal Akuntansi dan Bisnis, 6(1), 104-119.

Sartono, A. (2010). Manajemen Keuangan Teori dan Aplikasi. Yogyakarta: BPFE Yogyakarta.

Sembiring, E.R. (2005). Karakteristik Perusahaan dan Pengungkapan Tanggung Jawab Sosial (Studi Empiris pada Perusahaan yang tercatat di Bursa Efek Jakarta), SNA VIII Solo.

Timothy, Y.C.K. (2010). Effects of Corporate Governance on Tax Aggressiveness. Hong Kong Baptist University. Diakses tanggal 22
Desember 2014 dari libproject.hkbu.edu.hk/trsimage/hp/ 07014341.pdf.

Undang-Undang Perpajakan No.28 tahun 2007 tentang Ketentuan Umum dan Tata Cara Perpajakan.

Undang-Undang No. 40 tahun 2007 Pasal 74 Tentang Perseroan Terbatas.

Winarsih, R. \& Kusufi, M. S. (2013). Pengaruh Good Corporate Governance dan Corporate Social ResponsibilityTerhadap Tindakan Pajak Agresif (Studi pada Perusahaan Manufaktur yang Listingdi BEI Tahun 2009-2012). SNA 17 Mataram.

Xynas, L. (2011). Tax Planning, Avoidance and Evasion in Australia 1970-2010: The Regulatory Responses and Taxpayer Compliance. Revenue Law Journal Vol.20 Issue.1.

Xynas, L. (2011). Tax Planning, Avoidance and Evasion in Australia 1970-2010: The Regulatory Responses and Taxpayer Compliance. Revenue Law Journal Vol.20 Issue.1.

Yoehana, M. (2013). Analisis Pengaruh Corporate Social Responsibility terhadap Agresivitas Pajak (Studi Empiris pada Perusahaan Manufaktur yang Terdaftar di Bursa Efek Indonesia Tahun 2010-2011) 